
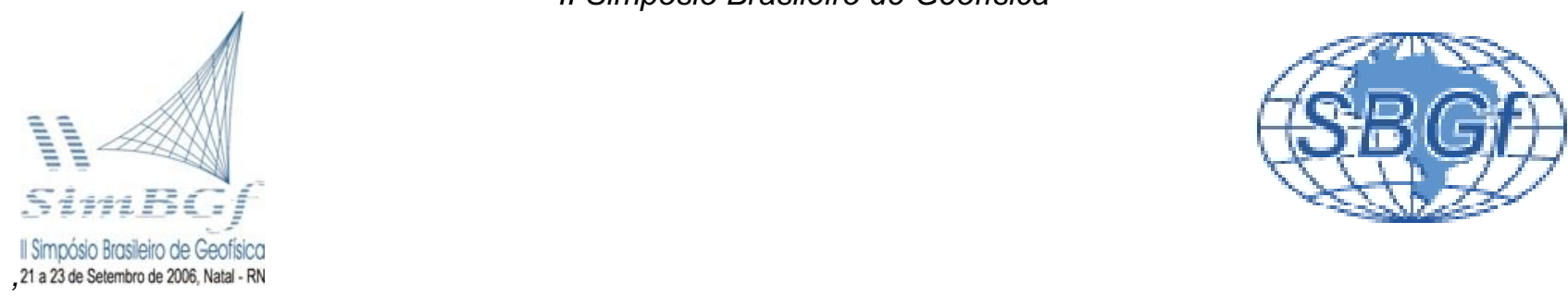

\title{
Estudo de anomalias gravimétricas na borda norte da Bacia do Paraná
}

Renato De F. Moraes, Vanderlei Coelho de O. Junior \& Yára Regina Marangoni.

Instituto de Astronomia, Geofísica e Ciências Atmosféricas da Universidade de São Paulo.

Copyright 2006, SBGf-Sociedade Brasileira de Geofísica

Este texto foi preparado para a apresentação no II Simpósio de Geofísica da

Sociedade Brasileira de Geofísica, Natal, 21-23 de setembro de 2006. Seu conteúdo foi revisado pela Comissão Tecno-científica do II SR-SBGf mas não necessariamente representa a opinião da SBGf ou de seus associados. E proibida a reprodução total ou parcial deste material para propósitos comerciais sem prévia autorização da SBGf.

\section{Resumo}

O presente trabalho tem como objetivo apresentar resultados obtidos de um modelamento direto confeccionado a partir de dados gravimétricos levantados na borda norte da Bacia do Paraná e com isto contribuir para uma melhor compreensão da distribuição de massa resultante dos processos geológicos ocorridos naquela região. O conjunto modelado consistiu da bacia com espessura de sedimentos variando de 0 a $4 \mathrm{~km}$, afloramento de basalto, com espessura de $180 \mathrm{~m}$, vinculado a observações de campo, diques básicos e ácidos. A espessura dos sedimentos e do basalto foi vinculada a resultados da função do receptor (apresentados neste Simpósio).

\section{Introdução}

A bacia do Paraná tem sido objeto de estudo gravimétrico ao longo das últimas décadas, porém a borda noroeste só foi recoberta por estações gravimétricas a partir de 1996 pelo IBGE. Vidotti et al. (1998) apresentaram um mapa Bouguer para a bacia com os dados gravimétricos disponíveis na época e mapearam um baixo gravimétrico na porção norte de bacia. Esse baixo alonga-se na direção NS e não apresenta correlação com as estruturas geológicas observadas em superfície, todas na direção preferencial EW.

Em 1997, o IBGE, completou o estudo gravimétrico do estado de Goiás, especialmente na porção SW, preenchendo um vazio no mapa apresentado por Vidotti et al. (1998) e melhorando a distribuição de pontos na área. O mapa Bouguer com os todos os dados disponíveis atualmente (Figura 1) mostra que a feição alongada detectada anteriormente continua até o limite norte da bacia e que a leste da mesma existe uma outra feição de menor extensão longitudinal. Os baixos têm amplitude de cerca de $20 \mathrm{mGal}$, circundados por fortes gradientes horizontais $(\sim 0,8 \mathrm{mGal} / \mathrm{km})$ e separados entre si por um alto gravimétrico de mesma amplitude. $O$ forte gradiente horizontal na anomalia Bouguer sugere uma fonte rasa para a anomalia, que não é prevista em função da geologia conhecida da bacia para a região, como salientado por Vidotti et al. (1998). Modelos iniciais desses baixos gravimétricos sugerem a presença de um sistema de dois grabens orientados N-S (Machado et al. 2001).

As espessuras do basalto e profundidades do embasamento obtidas com o modelamento da Função do Receptor de An \& Assumpção (2004 a, b) são compatíveis com o que se conhece da Bacia do Paraná baseado nos poucos poços profundos já perfurados. As profundidades do embasamento no local analisado variam de 1 a $4 \mathrm{~km}$.

Este trabalho apresenta resultados obtidos através do estudo de duas anomalias gravimétricas negativas encontradas. As análises consistiram em, primeiramente, densificar o levantamento dos dados da região através de perfis com estações espaçadas de cerca 4-5 km, cortando longitudinalmente as anomalias, analisar o regional e fazer modelamento direto (2,5D). Para diminuir a ambigüidade da resposta, informações de Função do Receptor (Costa et al., 2006) integradas aos dados gravimétricos foram utilizadas.

\section{Metodologia}

Os perfis foram completados (Goiás, Mato Grosso e Mato Grosso do Sul) no segundo semestre de 2005 e com isso, a geração de mapas para uma análise mais eficiente foi elaborada. O levantamento gravimétrico foi realizado com Gravímetro LaCoste \& Romberg, Modelo G. As anotações de cada estação foram realizadas numa tabela padronizada e nela consta o ponto medido (coordenadas), hora precisa da medição intermediária de um conjunto de 3 (três) medidas, altimetria, sendo que estas informações são utilizadas para as correções relacionadas aos Astros (interferência da Lua e do Sol) e da posição geográfica.

As coordenadas geodésicas foram obtidas por posicionamento com receptor GPS de dupla freqüência, no modo relativo usando a RBMC (IBGE, 2004), com monitoramento contínuo por 15 min. $O$ geóide gravimétrico da América do Sul (Sá, 2004) foi usado no processo de transformação de altitudes geométricas para ortométricas. Em seguida foi realizada a redução dos dados coletados, que transforma as leituras do equipamento em acelerações e anomalias de gravidade. Primeiramente fazem-se as correções de variações temporais do campo de gravidade causadas pela atração luni-solar, resultando no valor de gravidade no ponto. Em seguida subtrai o valor da gravidade normal para estação, fornecida pela fórmula do Sistema Geodésico de Referência de 1967, do valor da correção Ar-livre para 
obter o valor da anomalia Ar-livre. Dando seguimento à redução, aplica-se sobre a anomalia Ar-livre a Correção Bouguer, para então obter a Anomalia Bouguer. Esse procedimento foi realizado através do programa REGRAV2 (Sá, 1994) e para a redução Bouguer utilizouse o valor de $2,67 \mathrm{~g} / \mathrm{cm}^{3}$ para densidade.

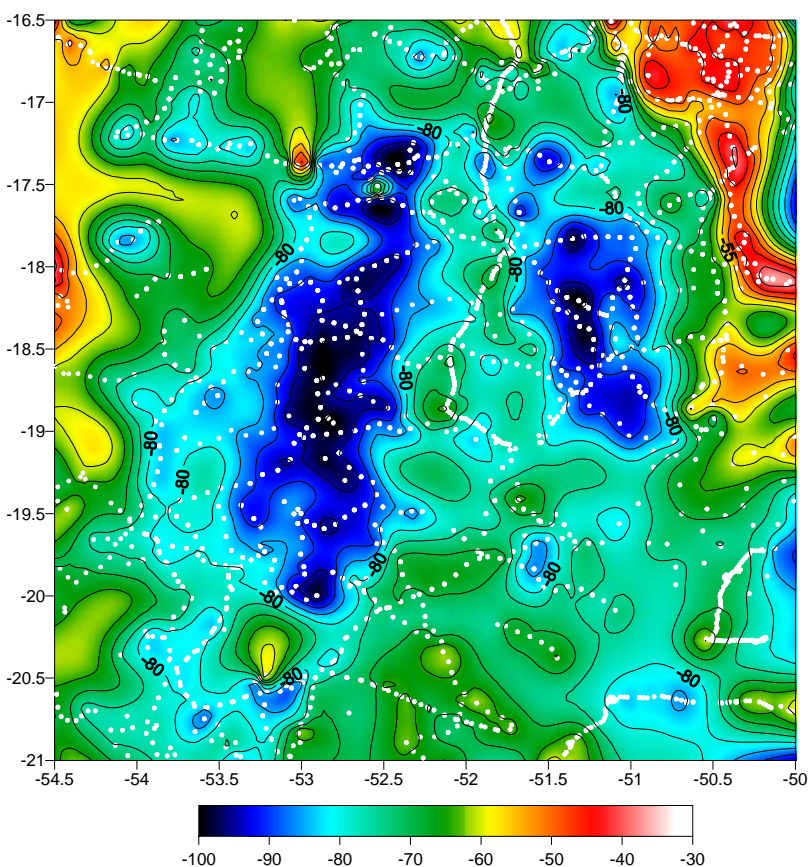

Figura 1 - Mapa de anomalia Bouguer da borda noroeste da Bacia do Paraná com a localização das estações gravimétricas.

Dados antigos do banco de dados do Grupo de Geodésia e Gravimetria do IAG-USP foram integrados à nova coleção, bem como dados do IBGE. Atualmente, pode-se utilizar 3572 dados no total (IAG-USP = 1621, IBGE = 1882 , nova coleta $=69$ ).

A interpolação dos dados para a realização do mapa foi baseada no método da mínima curvatura, pois a superfície estimada é independente da distribuição dos dados e da presença de ruído, além de manter contornos fiéis aos dados originais e produzir uma única solução. $\mathrm{Na}$ análise do regional foi utilizada a continuação para cima em vários níveis, com o propósito de tentar delimitar melhor as possíveis fontes gravimétricas das anomalias negativas. Para isto calcula-se a transformada rápida de Fourier (FFT) do campo gravitacional ao nível da superfície ou do levantamento aéreo, mantendo-se os coeficientes de Fourier calculados nas direções $x$ e $y$ (longitude e latitude) e tendo a altitude (z) como única variável. A continuação para cima tende a atenuar as anomalias de curto comprimento de onda (ou alta freqüência), e manter aquelas de maior comprimento de onda, dependendo da altura $z$ de continuação. Portanto, é possível utilizar esta transformação para estimar a componente regional no processo de separação das anomalias com diferentes profundidades de origem.

Nesta análise do regional também foi utilizada a análise de regressão (linha de tendência), que neste caso mostrou-se mais eficaz quanto à análise dos problemas de previsão.

No modelamento direto foi utilizado o programa GravMag (Pedley et al 1993), o qual é baseado no algoritmo de Talwani et al (1959). Segundo esse trabalho, muitos corpos e estruturas geológicas podem ser simplificados quando se utilizam estruturas lineares. Isto nos permite ajustar polígonos bidimensionais de $\mathrm{n}$ lados, variando-se a profundidade e distância ( $x, z)$, a livre arbítrio do operador, bem como o número de lados. Os vínculos geológicos são imprescindíveis na fase de modelamentos, pois, a bem da verdade, o operador que utiliza o algoritmo de Talwani, pode construir polígonos de variadas formas e escolher densidades fictícias que, embora façam a curva calculada aproximar-se da curva do perfil medido, podem não apresentar sentido geológico, sendo este um dos grandes problemas dos métodos potenciais.

\section{Resultados}

O primeiro passo deste projeto foi escolher um perfil adequado para seu respectivo modelamento. O perfil utilizado está localizado na latitude $18,5^{\circ}$ sul e entre as longitudes $54,5^{\circ}$ a $50^{\circ}$ oeste. Nestas coordenadas podemos analisar as duas anomalias negativas onde as suas amplitudes são maiores. Próximas a este perfil estão localizadas as estações sismológicas onde foram coletadas informações da Função do Receptor. Também foram identificados em campo afloramentos de basalto, contribuindo para a confecção do modelo direto.

Posteriormente, foram realizados 17 processos de continuação para cima, abrangendo valores de 5 a 200 $\mathrm{km}$, porém nenhum campo residual obtido destes processos foi eficiente no modelamento das anomalias gravimétricas negativas da Bacia do Paraná. Este fato pode ser visualizado nas figuras 2, 3, 4, 5 e 6 em que a diferença numérica obtida entre os valores medidos (em rosa) e o regional (em azul) produz um perfil residual inconveniente para o modelamento direto.

Ao contrário desse fato, uma linha de tendência utilizando um polinômio de segundo grau foi ajustada aos dados contribuindo muito mais para o modelo final obtido. A linha de tendência e o perfil residual podem ser visualizados nas Figuras 7 e 8.

Após a verificação do melhor regional a ser utilizado no modelamento, também foram agregadas informações geológicas e da Função do Receptor. Na Tabela 1, as coordenadas e as profundidades dos sedimentos da bacia relacionadas com o perfil utilizado podem ser visualizadas. 


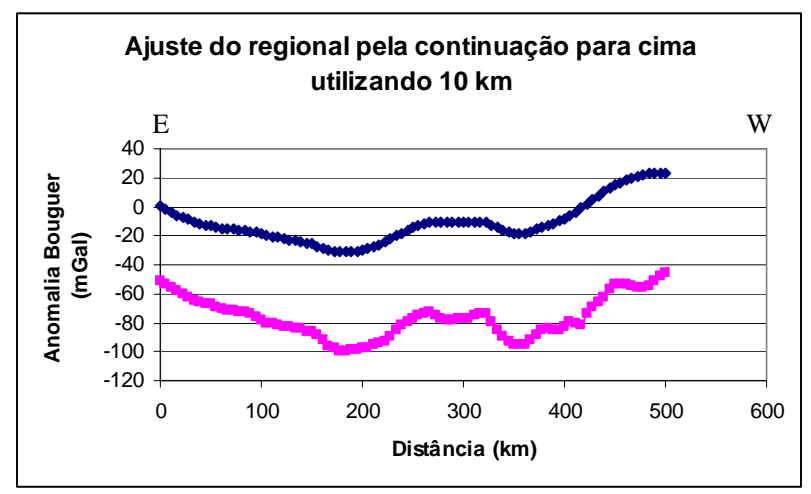

Figura 2 - Gráfico do ajuste regional (10km).

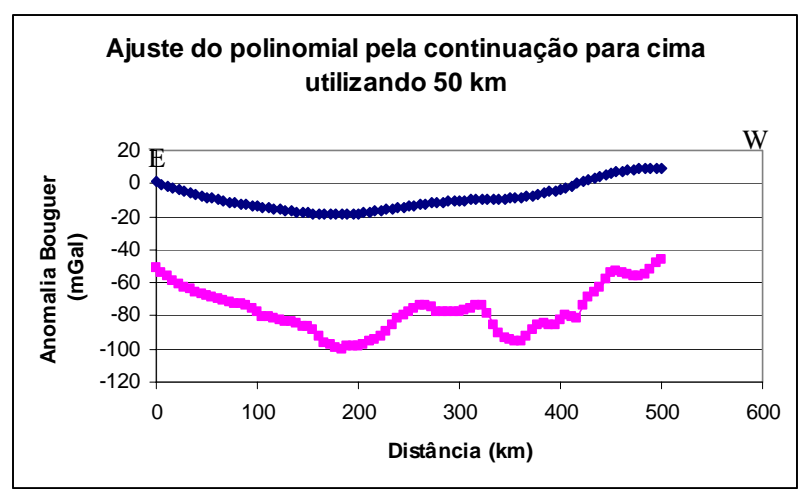

Figura 3 - Gráfico do ajuste regional $(50 \mathrm{~km})$.

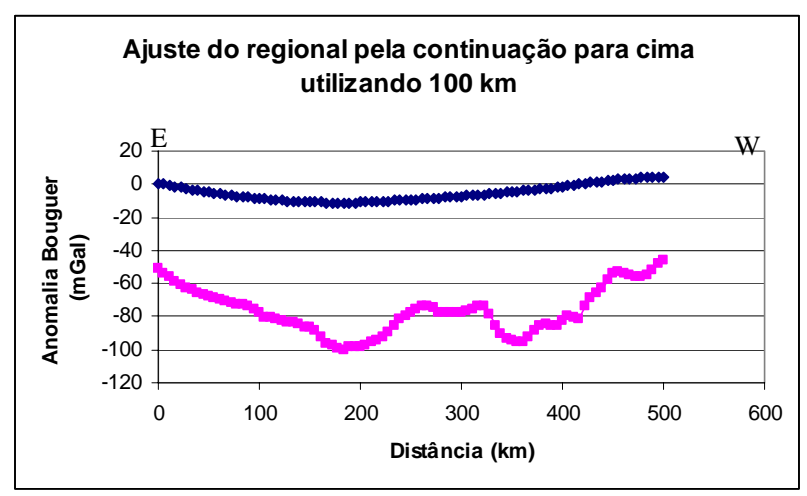

Figura 4 - Gráfico do ajuste regional $(100 \mathrm{~km})$.

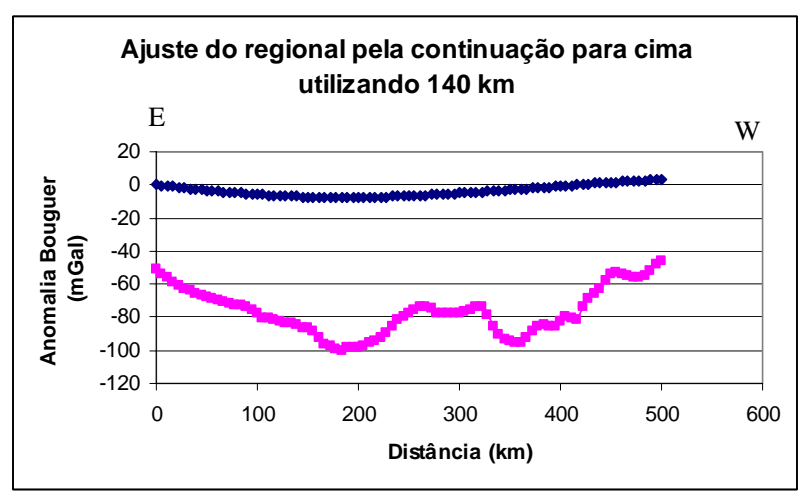

Figura 5 - Gráfico do ajuste regional $(140 \mathrm{~km})$.

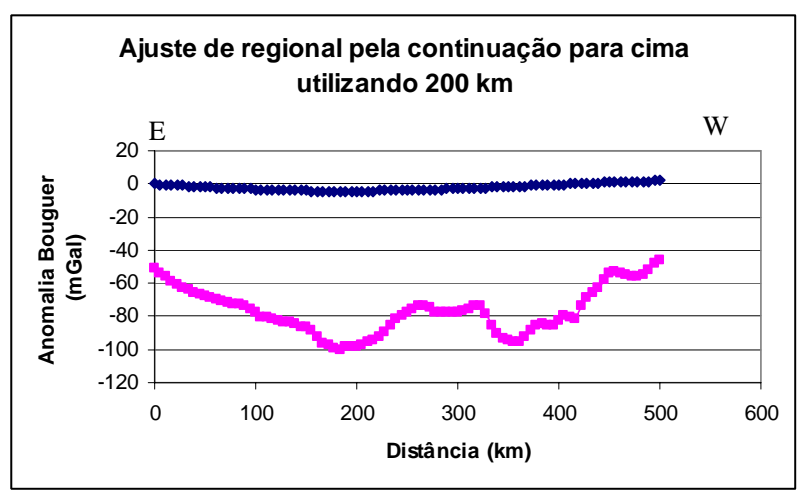

Figura 6 - Gráfico do ajuste regional $(200 \mathrm{~km})$.

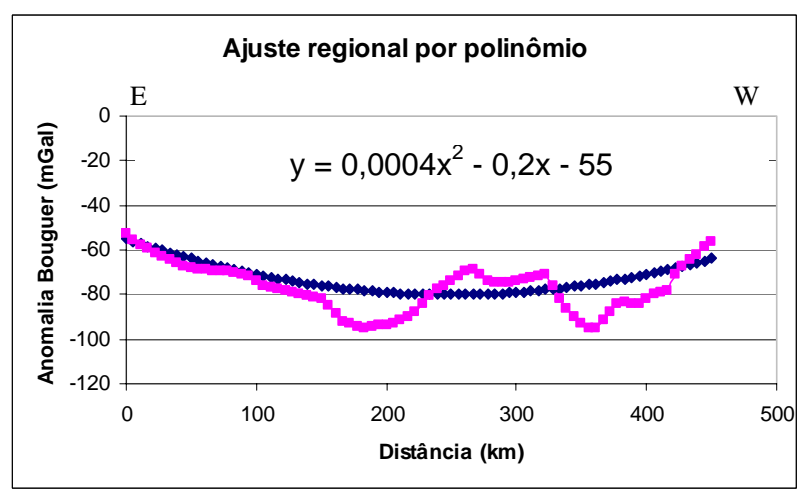

Figura 7 - Gráfico do ajuste regional (polinômio de $2^{\circ}$ ).

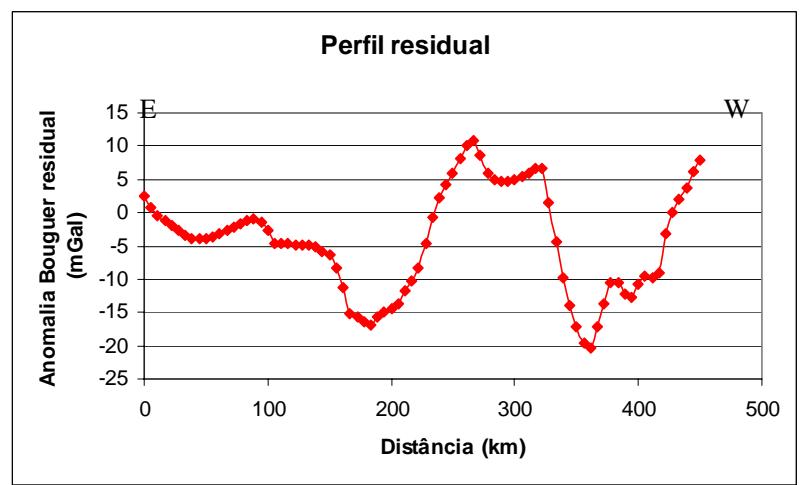

Figura 8 - Gráfico do perfil residual.

\begin{tabular}{|c|c|c|c|}
\hline Estação & Latitude $\mathbf{(}^{\mathbf{}}$ ) & Longitude $\mathbf{(}^{\mathbf{}}$ ) & Profundidade (km) \\
\hline APOB & $-18,54711$ & $-52,02507$ & 3,4 \\
\hline CDSB & $-18,76547$ & $-52,83928$ & 4,0 \\
\hline CCUB & $-18,42526$ & $-51,21258$ & 2,2 \\
\hline CMPA & $-19,57922$ & $-54,16877$ & 2,2 \\
\hline JATB & $-17,89290$ & $-51,49290$ & 3,3 \\
\hline
\end{tabular}

Tabela 1 - Função do Receptor (adaptado de Costa et al., 2006).

Foram realizados vários modelos, porém o que ajustou melhor os dados foi o modelo apresentado pela Figura 9, em que um enxame de diques pode ser visualizado logo abaixo da bacia. Os sedimentos apresentam-se na cor amarela e os diques nas cores azul e verde.

Para se aproximar de uma feição esperada, o conjunto modelado consistiu de: 0 a $4 \mathrm{~km}$ de sedimentos $(2,65$ 
$\left.\mathrm{g} / \mathrm{cm}^{3}\right), 180 \mathrm{~m}$ de basalto aflorando $\left(2,8 \mathrm{~g} / \mathrm{cm}^{3}\right)$, diques básicos $\left(a z u l=2,85 \mathrm{~g} / \mathrm{cm}^{3}\right.$ ) e ácidos $\left(\right.$ verde $=2,7 \mathrm{~g} / \mathrm{cm}^{3}$ ) e crosta terrestre como background $\left(2,75 \mathrm{~g} / \mathrm{cm}^{3}\right)$.

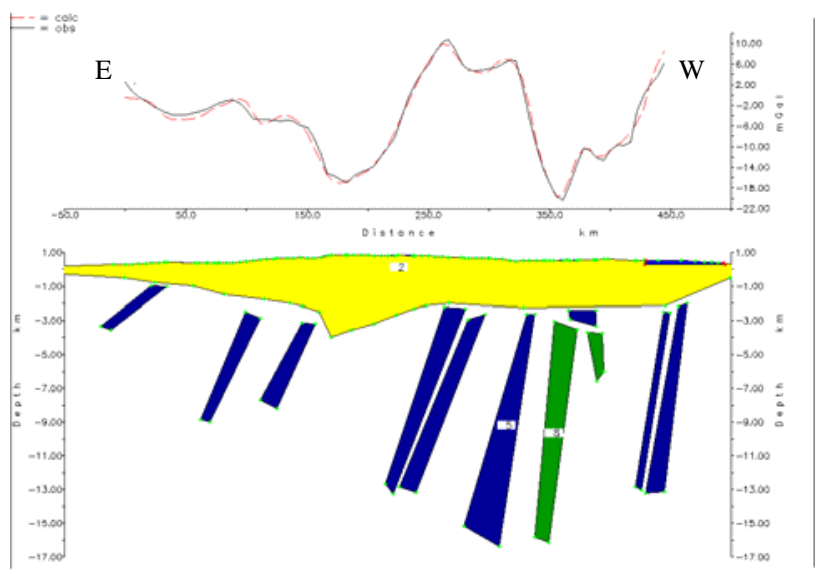

Figura 9 - Modelo direto confeccionado através do perfil residual.

\section{Discussão e Conclusões}

O perfil residual gerado pelo ajuste matemático proveniente do polinômio de segundo grau foi considerado o melhor. Os perfis residuais resultantes das continuações para cima levaram a modelos incompatíveis com a geologia da região. Usando a interface sedimentoembasamento dada por dados sismológicos seria necessário modelar corpos com densidades muito maiores do que as esperadas para a crosta superior.

O modelo gravimétrico apresentado na Figura 9 ajusta bem a curva de anomalia Bouguer residual para este perfil retirado do mapa de anomalia Bouguer (Figura 1) da região da Bacia do Paraná.

Para este local não são encontrados derrames basálticos e consideramos que o corpo de basalto que aflora a oeste do perfil é proveniente de intrusões magmáticas. Para uma melhor visualização e entendimento do modelo a continuação dos diques dentro da bacia não foi apresentada, porém estes devem chegar próximos à superfície e devem ser as fontes para a camada de rochas básicas no limite leste do perfil.

Os surgimentos de corpos ácidos que explicam a anomalia gravimétrica negativa à oeste do perfil estão apresentados como diques que possuem menores densidades (corpos de cor verde).

Enfatizamos que este modelo pode ser modificado devido a novas informações futuras que poderão contribuir para o entendimento destas anomalias gravimétricas negativas na borda da Bacia do Paraná e que este modelo não é único.

\section{Agradecimentos}

Agradecemos ao grupo de sismologia do IAG-USP, especialmente ao aluno de mestrado Thiago Nobre, que foi o responsável pelas informações de Função do Receptor utilizadas no modelamento.

Agradecemos à Fapesp, processo 05/51035-2.

\section{Referências}

An, M. \& Assumpção, M., 2004a. Multi-objective inversion of surface waves and receiver functions by competent genetic algorithm applied to the crustal structure of the Paraná Basin, SE Brazil: Geophys. Res. Lett., Vol. 31(5), L05615, 10.1029/2003GL019179.

An, M. \& Assumpção, M., 2004b. Basement depth in the Paraná Basin with high frequency receiver functions. I Simpósio de Geofísica da SBGf, São Paulo, 2628/09/2004.

Costa, T.N., Assumpção, M. \& Barbosa, J.R., 2006. Estudo de espessura sedimentar na bacia do Paraná com função do receptor de alta freqüência. II Simpósio brasileiro da SBGf, Natal.

IBGE (Fundação Instituto Brasileiro de Geografia e Estatística), 2004. http://www.ibge.gov.br

Machado, B.L., Carminatti, M.G. \& Marangoni, Y.R., 2001. Anomalias gravimétricas na borda norte da Bacia do Paraná, 7. Congresso Internacional da SBGf, Salvador, sessão PS4, 739-741.

Pedley, R.C., Busby, J.P. e Dabek, Z.K. ,1993. GRAVMAG User Manual - Interactive 2.5D Gravity \& Magnetic Modelling. Britsh Geological Survey, Tecnical Report WK/93/26/R, 73p.

Sá, N. C., 1994. Redução de observações gravimétricas, teoria e prática. Universidade de São Paulo, IAG-USP, departamento de geofísica.

Sá, N.C. de, 2004. O campo de gravidade, o geóide e a estrutura crustal na América do Sul. Tese de livredocência, IAG-USP, São Paulo, 121 pp

Talwani, M., Worzel, J. L., Landisman, M., 1959. Rapid gravity computations for two dimensional bodies with application to the mendoncino submarine fracture zonel. J. Geophys. Res. 64, 49\{59\}

Vidotti, R.M., Ebinger, C.J. \& Fairhead, J.D., 1998. Gravity signature of the western Paraná basin, Brazil: Earth, Planet. Sci. Lett., 159, 117-132. 